\title{
Research in psychotherapy and psychoanalysis
}

\author{
David A Shapiro University of Sheffield
}

\section{Author's abstract \\ Wilkinson's (1) critique of psychoanalysis and psychoanalytically oriented psychotherapy is weakened by inconsistent use of crucial terms, a systematically biased selectivity in reviewing empirical evidence and prior debates, and a failure to address issues crucial for a scientific understanding of psychotherapy.}

Wilkinson (1) has questioned the place of psychoanalysis and psychoanalytically oriented psychotherapy in the National Health Service (NHS). His argument is weakened by inconsistent use of crucial terms, a systematically biased selectivity in references to empirical evidence and prior debates, and a failure to address the crucial issues for understanding and evaluating psychotherapy.

In order to unravel the confusion brought about by Wilkinson's careless use of terminology, we must distinguish between 'psychotherapy' and 'psychoanalysis'. 'Psychotherapy' is generally used, in the scientific literature, in a broad and inclusive sense:

'The informed and planful application of techniques derived from established psychological principles, by persons qualified through training and experience to understand these principles and to apply these techniques with the intention of assisting individuals to modify such personal characteristics as feelings, values, attitudes and behaviours which are judged by the therapist to be maladaptive or maladjustive' (2).

Within this broad class of psychotherapies, psychoanalysis, as described in the account from Dare (3) used by Wilkinson to identify the target of his attack, is a highly specific subtype, not normally practised within the NHS and itself the subject of remarkably little evaluative research. It is highly misleading of Wilkinson to imply thereby that the psychiatrists, nurses, social workers, counsellors and clerics to whom he refers are carrying out psychoanalysis involving up to two hundred hours of

\section{Key words}

Psychoanalysis; psychoanalytic psychotherapy; effectiveness of psychotherapy; National Health Service. therapy per patient per year, using traditional, passive technique, and conceptualised at a high level of theoretical abstraction. In practice, these professions are perforce guided by resource constraints towards brief psychotherapy or longer-term 'maintenance' work which may prevent hospitalisation and maintain the patient's active contribution to the community. Of course, it is true that much of this work is influenced by psychoanalytic principles or derivatives thereof; but this does not mean that it fits Dare's description. Wilkinson's inconsistent use of terminology gives illusory force to his strictures against the costeffectiveness of psychotherapeutic services, by implying that these are more costly per patient treated than is in fact the case.

Wilkinson's (1) account of research on the efficacy of psychotherapy is similarly riddled with terminological confusion. In this discussion, he appears to use the terms 'psychoanalysis/ psychoanalytic' and 'psychotherapy/ psychotherapeutic' interchangeably. A tiny proportion, at most, of the studies included in metaanalytic reviews involve psychoanalysis. These reviews address the evaluation of psychotherapy in general, rather than of psychoanalysis.

None the less, it is worth considering whether Wilkinson's account of the scientific literature is fair to psychotherapy. In fact, his citation of empirical evidence $\frac{?}{0}$ and prior debate is misleadingly biased against psychotherapy's effectiveness. The small-scale Prioleau o et al (4) meta-analysis and the Brodaty and Andrews (5) trial are outweighed by large amounts of evidence not 0 mentioned by Wilkinson, but cited, for example, by $\omega$ Bloch and Lambert (6), whose critique of a position similar to Wilkinson's is dismissed in the following sentence: 'Despite this, the psychotherapy lobby seems $\stackrel{\oplus}{\overparen{D}}$ unruffled'. The study by Sloane et al (7) is dismissed as : yielding 'rather inconclusive results', which is hardly a fair account of a study showing a clear advantage to $\frac{\mathbb{D}}{\mathbb{D}}$

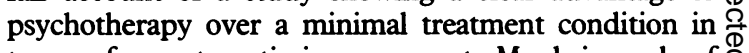

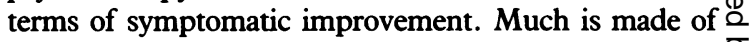
the fact that 'no less than five editorials in prominent medical journals' have criticised the empirical basis for 8 psychotherapy on the basis of the single Prioleau et al article, but no mention is made of the critiques published in Behavioural and Brain Sciences alongside that article. 
When addressing the question of general practitioners' evaluations of general outpatient psychiatric services $\mathbf{v}$ specialised psychotherapy, Wilkinson overinterprets the results of a single survey (8) apparently supporting his position. He does not consider the objections that GPs will see the general psychiatric outpatient clinic as the appropriate gateway to more specialist services judged appropriate by the general psychiatrist, and that no inference based on the particular local conditions of one health district can be generalised to other districts with different traditions and personnel. Readers of Wilkinson's account will be surprised to learn from the original that 75 per cent of the GPs completing the questionnaire described individual psychotherapy as very/fairly useful; he reports that individual psychotherapy was ranked seventeenth in order of usefulness, a presentation that much better suits his purpose.

Thus far, I have given examples of how Wilkinson's article is misleading in its use of terms, and is short on scholarship and long on biased polemic. Finally, let us turn, more constructively, to issues not addressed by Wilkinson, which urgently require attention if psychotherapy is to be placed on a secure scientific footing.

Taken as a whole, empirical evidence on the efficacy of psychotherapy suggests that it is, in general, effective (9, 10); however, there is remarkably little evidence that different forms of psychotherapy - from psychoanalysis to behaviour therapy - differ in their effectiveness, despite manifest discrepancies in their theoretical rationales and empirically demonstrated differences in what therapists actually say and do during sessions (11). Thus, what we urgently need is research designed to identify the therapeutic ingredients of readily specified, teachable, and economically implementable psychotherapies; recent developments have shown such studies to be feasible $(12,13,14)$, contrary to earlier pessimism based upon the failure of older research strategies (15). Such research will not only tell us which psychotherapies are most effective for what problems, but also help us to satisfy the pressing scientific requirement to identify mechanisms of change.

David A Shapiro PhD leads a group of clinical psychologists studying the process and outcomes of psychotherapy at the Medical Research Council/Economic and Social Research Council Social and Applied
Psychology Unit, Department of Psychology, the University of Sheffield, and was until recently Editor of the British Journal of Clinical Psychology.

\section{References}

(1) Wilkinson G, Psychoanalysis and analytic psychotherapy in the NHS - a problem for medical ethics. Fournal of medical ethics 1986; 12: 88-91.

(2) Meltzoff J, Kornreich M. Research in psychotherapy. New York: Atherton, 1970.

(3) Dare C. Psychoanalysis. In: Harré R, Lamb R, eds. The encyclopaedic dictionary of psychology. Oxford: Blackwell, 1983.

(4) Prioleau L, Murdock M, Brody N. An analysis of psychotherapy versus placebo studies. Behavioural and brain sciences; 1983; 6: 275-310.

(5) Brodaty H, Andrews G. Brief psychotherapy in family practice: a controlled prospective intervention trial. British journal of psychiatry 1983; 143: 11-19.

(6) Bloch S, Lambert M J. What price psychotherapy? A rejoinder. British journal of psychiatry 1985; 146: 96-98.

(7) Sloane R B, Staples F R, Cristol A H, Yorkston N J, Whipple K. Psychotherapy versus behaviour therapy. Cambridge, Mass: Harvard University Press, 1975.

(8) Crisp A H, Hemsi L K, Paykel E S, Storey P B, Beary M D, Kerr D L. A future pattern of psychiatric services and its educational implications: some suggestions. Medical education, 1984; 18: 110-116.

(9) Smith M L, Glass G V, Miller T I. The benefits of psychotherapy. Baltimore: Johns Hopkins University Press, 1980.

(10) Shapiro D A, Shapiro D. Meta-analysis of comparative therapy outcome studies: a replication and refinement Psychological bulletin 1982; 92: 581-604.

(11) Stiles W B, Shapiro D A, Elliott R K. Are all psychotherapies equivalent? American psychologist 1986; 41: 165-180.

(12) Goldberg D P, Hobson R F, Maguire G P, Margison F R, O'Dowd T, Osborn M S, Moss S, The clarification and assessment of method of psychotherapy. British journal of psychiatry 1984; 144: 567-575.

(13) Maguire G P, Goldberg D P, Hobson R F, Margison F R, Moss S, O'Dowd T. Evaluating the teaching of a method of psychotherapy. British joumal of psychiatry 1984; 144: 576-580.

(14) Shapiro D A, Firth J A. Prescriptive vs exploratory psychotherapy: outcomes of the Sheffield Psychotherapy Project. British journal of psychiatry (in press).

(15) Candy J, Balfour F H G, Cawley R F, Hildebrand H P, Malan D H, Marks I M, Wilson J. A feasibility study for a controlled trial of formal psychotherapy. Psychological medicine 1972; 2: 345-362. 